\title{
Protein-energy malnutrition among preschool children in Oman: results of a national survey
}

D. Alasfoor, ${ }^{1}$ M.K. Elsayed, ${ }^{2}$ A.M. Al-Qasmi, ${ }^{3}$ P. Malankar, ${ }^{4}$ M. Sheth ${ }^{5}$ and N. Prakash ${ }^{6}$

$$
\begin{aligned}
& \text { سوء التغلية بالبروتين والطاقة بين الأطفال دون سن المدرسة في سلطنة عُمان - نتائج مسح وطني }
\end{aligned}
$$

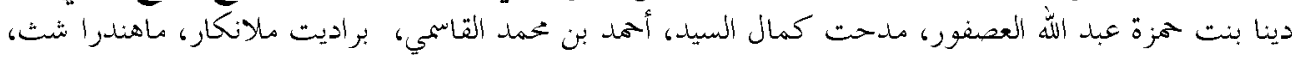

$$
\begin{aligned}
& \text { نيتيا براكاث }
\end{aligned}
$$

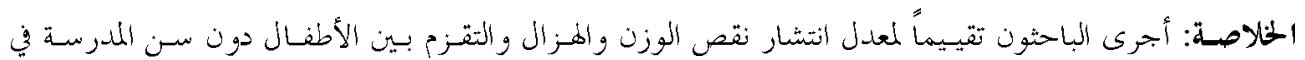

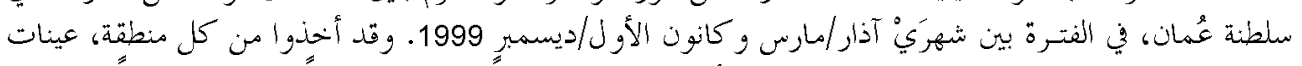

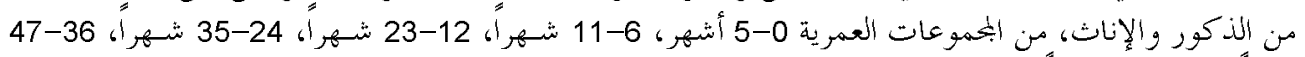

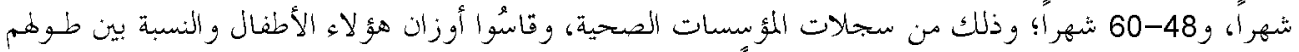

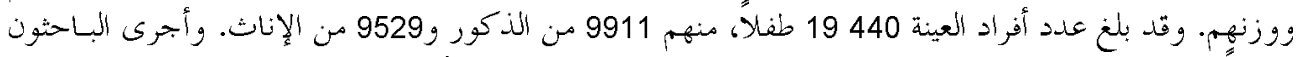

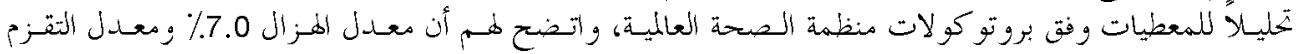

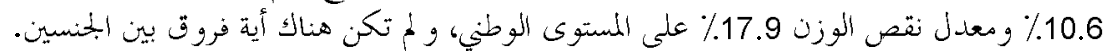

ABSTRACT We assessed the prevalence of underweight, wasting and stunting among preschool children in Oman from March to December 1999. Within each region, samples of males and females in the age groups $0-5,6-11,12-23,24-35,36-47$ and 48-60 months were drawn from the registers of health institutions and the weight and height/length of the children were measured. The total sample comprised 19440 children; 9911 males and 9529 females. Data were analysed according to the World Health Organization protocols. The prevalence rates of wasting, stunting and underweight were $7.0 \%$, $10.6 \%$ and $17.9 \%$ respectively at the national level. There were no sex differences.

La malnutrition protéinocalorique chez l'enfant d'âge préscolaire à Oman : résultats d'une enquête nationale

RÉSUMÉ Entre mars et décembre 1999, nous avons évalué la prévalence de l'insuffisance pondérale, de l'émaciation et du retard de croissance staturale chez des enfants d'âge préscolaire à Oman. Dans chacune des régions, nous avons prélevé dans les registres des établissements de santé des échantillons d'enfants des deux sexes appartenant aux tranches d'âge 0-5, 6-11, 12-23, 24-35, 36-47 et 48-60 mois et mesuré le poids et la longueur/taille des enfants. L'échantillon total englobait 19440 enfants, à savoir 9911 garçons et 9529 filles. L'analyse des données a été effectuée conformément aux protocoles établis par l'Organisation mondiale de la Santé (OMS). À l'échelon national, les taux de prévalence de l'émaciation, du retard de croissance staturale et de l'insuffisance pondérale sont respectivement de $7,0 \%, 10,6 \%$ et $17,9 \%$. II n'apparaît aucune différence liée au sexe.

${ }^{1}$ Department of Nutrition; ${ }^{2}$ Department of Health Information and Epidemiology; ${ }^{3}$ Department of Health Information and Statistics, ${ }^{4}$ Ministry of Health, Muscat, Oman (Correspondence to D. Alasfoor: omanmgrs@ omantel.net.om).

${ }^{5}$ United Nations Children's Fund, Muscat, Oman.

${ }^{6}$ Follow-up section, Directorate General of Health Affairs, Ministry of Health, Oman, Egypt.

Received: 13/07/05; accepted: 15/11/05 


\section{Introduction}

Protein-energy malnutrition (PEM) has been identified by the World Health Organization (WHO) as the most lethal form of malnutrition, indirectly or directly causing an annual death of at least 5 million children worldwide [1]. Estimates indicate that $35.8 \%$ of preschool children in developing countries are underweight, 42.7\% are stunted and $9.2 \%$ are wasted [2]. These children are at higher risk of mortality and morbidity, and may carry adverse health and mental consequences all through their lives. Most of them live in poor societies, and with impaired physical and mental capacities they are bound to enter a vicious cycle of poverty and malnutrition for generations to come.

The child malnutrition rate in the Middle East has been reported to be $19 \%$, with varying rates, such as $39 \%$ in the Islamic Republic of Iran, 19\% in Egypt, 8\% in the United Arab Emirates and 6\% in Morocco [3]. The prevalence of underweight in Oman was found to be $62.9 \%$ in 1980 , and dropped to $24.4 \%$ and $23.6 \%$ in 1992 and 1995 respectively [4-6]. Although the prevalence of PEM declined by almost two-thirds between 1980 and 1995, it is well above countries with comparable health and economic indicators; consequently PEM is considered a major public health problem in Oman.

This survey was a collaborative effort of the Directorate General of Health Affairs, Departments of Health Information and Statistics as well as the United Nations Children's Fund (UNICEF) and WHO country offices in Muscat, Oman. It was conducted to generate baseline data on the prevalence of PEM among infants and children up to the age of 5 years at both the national and regional levels. Specifically, the study was designed to provide estimates of under- weight, wasting and stunting among male and female infants and young children in each of the age categories of $0-5,6-11$, $12-23,24-35,35-47$ and $48-60$ months at the national and regional levels.

\section{Methods}

\section{Sampling and sample size}

The sample was selected from the total population of children between the ages of 0 and 5 years in the child health registers of primary health care institutions in Oman between March and December 1999. No national surveys have been conducted since then. The coverage rate of the child health register was found to be $99.9 \%$ in 1995 [7]; therefore it was considered to be representative of the population studied and therefore a suitable sampling frame. The health registers of the sampled institutions in Muscat, Dhakhilia, Dhofar, North Sharqia, South Sharqia, North Batina, South Batina, Dhahira, Musendem and Wusta were stratified into age groups of $0-5$ months, 6-11 months, 12-23 months, 24-35 months, 36-47 months, and 48-60 months.

Sample size calculations were based on a minimum prevalence of underweight of $9 \%$, precision estimate of $25 \%$, confidence interval of $95 \%$ and a $10 \%$ non-response rate. The calculations were run on the STATCALC module of Epi-Info, version 6 software (WHO/CDC) and resulted in a national sample size of 9911 for males and 9529 for females, a total of 19440 children.

In each region, the regional hospital, a wilayat (district) hospital and a local hospital were selected and 2 small and 2 large health centres were randomly selected. In the first phase of the survey the plan was to distribute the sample as much as possible; so in the first 2 regions all the health insti- 
tutions were taken. This was found to be extremely demanding and inefficient so for the rest of the regions a sample of the health institutions was taken.

Thus for North and South Sharqia all health institutions were included in the sample and weighting was carried out to account for disproportionate sample sizes during data analysis. Al Wusta region was excluded from the study because of logistic problems; this did not affect the national estimates because of the small population size in that region.

To ensure adequate sampling, the most recent records of children in the child health register of the selected institutions were reported to the Department of Statistics categorized by age group and sex. These were randomized electronically using multistage stratified cluster sampling. The strata were the regions and the clusters were the institution levels within the regions, i.e. primary health care centres and regional and wilayat hospitals.

The study sample was drawn in the Department of Statistics 2 weeks before data collection in each region to avoid shifting of age groups with time, which could result in under-sampling of neonates. Systematic random sampling was used to sample children and non-Omanis were replaced.

\section{Equipment, standardization and training}

The UNICEF mother and child weighing scale (UNISCALE) was the standard weighing scale used in this survey. Children below 2 years were weighed in their mother's arms and older children were weighed standing. The Starter Baby Measure Mat was used to measure the length of children below 2 years and the Leicester Portable Measure was used to measure height of older children (both from CMS Weighing Equipment, United Kingdom).
To calibrate the weighing scales, sets of 5, 20-lb gym blocks were weighed to the 4 th decimal point in kilograms, and the weight of each block was pasted on it. The length measuring equipment was calibrated against 60, 100 and $150 \mathrm{~cm}$ calibration rods (CMS Weighing Equipment, United Kingdom).

The weighing and measuring of children was carried out according to the recommended WHO protocol [7]. A study manual of the methods, description of equipment, calibration, recruitment, measurement and recording instructions was complied and distributed to all the participants (master trainers and data collectors) and used for training.

An international anthropometric specialist introduced the master trainers (regional supervisors) to the theory considerations of anthropometry through demonstrations and individual practical sessions, a standardization exercise, and the calibration and quality control procedures. WHO reliability sheets were used to calculate the technical errors of measurement and biases of each observer (both master trainers and data collectors), and feedback was given at the end of the session. The group performed well; the average length measurement was $0.35 \mathrm{~cm}$ longer than the gold standard and the average height measurements was 0.2 $\mathrm{cm}$ lower. The gold standard was the data of the person who was considered the most experienced. So during the master trainers training; the international consultant was the gold standard. In data collectors' trainings, the master trainer was considered the gold standard.

All those involved in data collection in each region were trained on the study methods, and went through a standardization session before starting the data collection. The regional supervisors and at least one member of the study team were responsible for the training and giving individual feed- 
back. Most of the data collectors performed well during the standardization sessions; the few individuals who displayed extreme bias were individually provided additional training.

\section{Data collection}

Information on each subject in the sample was extracted from the MR2 registers and recorded in the study enrolment booklets during training, along with the MR2 numbers, and mother's name, address and contact number. These data, as well as unique subject numbers, were copied into the data collection booklets. Children were recruited by telephone wherever possible, and the measuring took place at the health institutions. The defaulters were followed up by telephone at least 2 times, and if they were not reached by home visiting, they were declared non-respondents on the form $(<8 \%)$.

The study team in each institution was composed of 2 trained anthropometrists, who conducted daily measuring sessions from 08:00 to 12:00. Calibration of the equipment was recorded before and after each session in log sheets. As the mother arrived at the study site, she was asked to take off all the clothes of her child and to dress him/her in a hospital gown. For each child, the 2 anthropometrists took weight and height measurements and they exchanged the anthropometrist/assistant roles for each measurement. The 2 measurements for each child were compared and if the difference exceeded $100 \mathrm{~g}$ for weight or $0.5 \mathrm{~cm}$ for height/length, the measurements were repeated. The regional supervisors paid regular visits to different study sites to monitor the implementation of the manual of operations and verify some measurements. In each region, infants at the age of 0-2 weeks were measured at the beginning of data collection, and all children were measured within 3 months of the beginning of data collection in that region.

The study forms were reviewed by the regional supervisors and the study coordinators at the central level for inconsistencies, completeness and pattern of measurements.

\section{Data entry and analysis}

Data entry was carried out on Epi-Info, version 6 using a specially designed data entry and check files. The Z-scores of weight-forage, height-for-age and weight-for-height were computed using the EPIANTH module of Epi-Info. The reference population was the NCHS/WHO, and age was calculated by subtracting the date of the anthropometric measurements from the date of birth.

A team of statisticians from the Department of Statistics performed the data cleaning, and preliminary analysis was done on the EPIANTH module of Epi-Info, where the prevalence of wasting, stunting and underweight for each region was calculated. Outliers were excluded in the analysis, and the files of all regions were then merged to a master file. To account for the variability introduced by unequal selection probabilities and response rates in cluster sampling, the "CSAMPLE" module of Epi-Info was used to calculate the prevalence estimates. A sample weight was calculated for each child, which was divided by the child's probability of selection, adjusted for refusal rates.

\section{Results}

The total sample comprised 19440 children; 9911 males and 9529 females. There were 1990 aged $0-5$ years, 1990 aged $6-11$ years, 3823 aged 12-23 years, 3801 aged 24-35 years, 4021 aged 36-47 years and 3815 aged $48-60$ years. 


\section{Underweight}

Moderate underweight is indicated by weight-for-age lower than $-2 \mathrm{SD}$ of the median reference NCHS/WHO population, and severe underweight is indicated by weight-for-age lower than $-3 \mathrm{SD}$ of the same population. The prevalence of underweight was estimated from those children falling below those cut-off points, and the mean (SD) of the Z-scores were determined in order to assess the distribution compared with the reference population (Table 1).

The prevalence of underweight among all children was $17.9 \%$ with no significant difference between males and females. At the age of $0-5$ months, the prevalence of underweight was $2.7 \%$, and the mean Zscore was almost the same as the reference population at that age $(-0.01)$. Underweight increased dramatically with age: it was $10.2 \%$ in the age group $6-11$ months, $21.4 \%$ for $12-23$ months, $22.8 \%$ for age group 24-35 months and $20.4 \%$ for age group 36-47 months. After the age of 4 years, underweight fell to $17.3 \%$. Severe underweight was observed in $1.5 \%$ of all children measured and showed the same age pattern (Table 1).

\section{Stunting}

Moderate and severe stunting were assessed as the prevalence of height-for-age below $-2 \mathrm{SD}$, and $-3 \mathrm{SD}$ of the reference NCHS/ WHO population respectively. The prevalence estimates and Z-scores were calculated to assess the distribution of stunting by age group and sex.

The overall prevalence of stunting was $10.6 \%$, with no significant differences between males and females. Stunting peaked at the age of 12-23 months, and then fell to about $10 \%-11 \%$ for children of $24-59$ months (Table 2).

\section{Wasting}

Wasting is an indicator of current nutritional health status, and is directly influenced by feeding behaviour, morbidity and house conditions. Moderate and severe wasting were assessed as the prevalence of weight-for-height below $-2 \mathrm{SD}$, and $-3 \mathrm{SD}$ of the reference NCHS/WHO population respectively. Overall, $7.0 \%$ of all children in the sample were below $-2 \mathrm{SD}$ of the reference population median (Table 3 ). The prevalence of wasting among males was $7.8 \%$, (CI: 6.7-8.9) whereas the prevalence

\begin{tabular}{|c|c|c|c|c|}
\hline \multirow{2}{*}{$\begin{array}{l}\text { Age group } \\
\text { (months) }\end{array}$} & \multirow{2}{*}{$\begin{array}{c}\text { Severe } \\
\text { underweight } \\
\%(95 \% \mathrm{Cl})\end{array}$} & \multirow{2}{*}{$\begin{array}{l}\text { Underweight } \\
\qquad \%(95 \% \mathrm{Cl})\end{array}$} & \multicolumn{2}{|c|}{ Z-score } \\
\hline & & & Mean & SD \\
\hline $0-5$ & $0.2(0.0-0.5)$ & $2.7(1.0-4.4)$ & -0.01 & 0.89 \\
\hline $6-11$ & $0.5(0.1-1.0)$ & $10.2(8.5-11.0)$ & -0.74 & 0.99 \\
\hline $12-23$ & $1.4(0.7-2.2)$ & $21.4(17.0-25.7)$ & -1.17 & 1.02 \\
\hline 24-35 & $2.9(1.5-4.2)$ & $22.8(18.4-27.1)$ & -1.24 & 0.96 \\
\hline $36-47$ & $2.2(0.6-3.8)$ & $20.4(16.6-24.3)$ & -1.26 & 0.94 \\
\hline $48-60$ & $0.8(0.4-1.2)$ & $17.3(14.9-19.8)$ & -1.19 & 0.88 \\
\hline Total & $1.5(1.2-1.9)$ & $17.9(15.9-19.9)$ & -1.08 & 1.01 \\
\hline
\end{tabular}




\begin{tabular}{|c|c|c|c|c|}
\hline \multirow{2}{*}{$\begin{array}{l}\text { Age group } \\
\text { (months) }\end{array}$} & \multirow{2}{*}{$\begin{array}{c}\text { Severe } \\
\text { stunting } \\
\%(95 \% \mathrm{Cl})\end{array}$} & \multirow{2}{*}{$\begin{array}{c}\text { Moderate } \\
\text { stunting } \\
\%(95 \% \mathrm{Cl})\end{array}$} & \multicolumn{2}{|c|}{ Z-score } \\
\hline & & & Mean & SD \\
\hline $0-5$ & $0.2(0.0-0.5)$ & $3.7(1.8-5.5)$ & -0.21 & 0.97 \\
\hline $6-11$ & $0.8(0.4-1.2)$ & $7.4(4.8-9.9)$ & -0.56 & 1.01 \\
\hline $12-23$ & $2.5(1.2-3.8)$ & $13.6(10.3-16.9)$ & -0.91 & 1.05 \\
\hline $24-35$ & $1.0(0.4-1.7)$ & $10.3(6.7-13.9)$ & -0.69 & 1.02 \\
\hline $36-47$ & $2.1(0.9-3.3)$ & $11.2(7.2-15.2)$ & -0.89 & 0.97 \\
\hline $48-59$ & $2.3(0.7-3.9)$ & $11.8(9.3-14.4)$ & -0.97 & 0.95 \\
\hline Total & $1.7(1.1-2.4)$ & $10.6(9.0-12.2)$ & -0.79 & 1.02 \\
\hline
\end{tabular}

among females was $6.2 \%$ (CI: 4.8-7.5), a non-statistically significant difference. The highest levels of wasting were observed among infants age 12-23 months where severe wasting was seen in $1.3 \%$ of the children compared with $0.3 \%$ and $0.2 \%$ in the $0-6$-month and 48-59-month age groups respectively. The rate of moderate wasting was also higher among the age group 12-23 months $(12.5 \%)$ than other age groups (Table 3).

\section{Regional estimates}

The prevalence of malnutrition indicators varied between regions of Oman. North Sharqia had the highest levels of PEM as $26.6 \%$ of the children in that region were underweight, $14.8 \%$ were stunted and $9.8 \%$ wasted. Dhakhilia, South Batina and Musendem had comparable results where $22.9 \%, 22.2 \%$ and $21.5 \%$ of the children respectively were underweight. Dhofar had the lowest levels of PEM; underweight in

\begin{tabular}{|c|c|c|c|c|}
\hline \multirow{2}{*}{$\begin{array}{l}\text { Age group } \\
\text { (months) }\end{array}$} & \multirow{2}{*}{$\begin{array}{c}\text { Severe } \\
\text { wasting } \\
\%(95 \% \mathrm{Cl})\end{array}$} & \multirow{2}{*}{$\begin{array}{l}\text { Wasting } \\
\%(95 \% \mathrm{Cl})\end{array}$} & \multicolumn{2}{|c|}{ Z score } \\
\hline & & & Mean & SD \\
\hline $0-5$ & $0.3(0.0-0.6)$ & $2.4(0.6-4.3)$ & 0.02 & 0.98 \\
\hline $6-11$ & 0.0 & $3.4(0.8-6.1)$ & -0.35 & 1.07 \\
\hline $12-23$ & $1.3(0.3-2.3)$ & $12.5(9.6-15.4)$ & -0.85 & 1.07 \\
\hline 24-35 & $0.3(0.05-0.6)$ & $6.7(5.5-7.8)$ & -0.87 & 0.82 \\
\hline $36-47$ & $0.4(0.1-0.7)$ & $7.4(5.9-8.9)$ & -0.84 & 0.91 \\
\hline $48-59$ & $0.2(0.001-0.4)$ & $5.3(4.2-6.5)$ & -0.76 & 0.87 \\
\hline Total & $0.5(0.2-0.7)$ & $7.0(6.0-8.0)$ & -0.71 & 0.98 \\
\hline
\end{tabular}


that region was $7.9 \%$, stunting $5.5 \%$ and wasting $4.0 \%$ (Figure 1).

\section{Age trends}

The prevalence rates of all the indicators of malnutrition were lower than $5 \%$ in the age group 0-5 months; underweight rates increased rapidly to $10 \%$ in the age group of $6-11$ months, to $>20 \%$ in the age groups 12-23 and 24-35 months. It declined slowly after the age of 3 years.

Stunting increased gradually up to the age of 2 years where it was $>10 \%$; then it declined gradually. Wasting, however, increased sharply between the age of 12 and 23 months, and then declined.

\section{Discussion}

Child nutritional status is an important indicator of health and development in countries. The Millennium Declaration signed by 189 countries in 2000 set a target of halving the prevalence of underweight of children under the age of 5 years by the year $2015[8,9]$.

In Oman, the prevalence of underweight is considered a public health problem of medium importance at the national level, but this varies between regions. Some have a high prevalence of underweight $(>20 \%)$ such as North Sharqia, Dhakhilia, South Batina and Musendem, whereas Muscat, Dhahira, North Batina and South Sharqia have a medium prevalence $(10 \%-20 \%)$. Dhofar has the lowest prevalence of underweight $(<10 \%)$.

At the national level, stunting in Oman is considered in the "poor" category, and all regions except Dhofar fall in that category [10]. When compared to previous studies, it is evident that PEM had declined markedly since 1980; De Onis et al. reported a 1\% annual reduction rate of stunting [11]. This trend was found to be consistent from 1991 up to 1999. In 1991, stunting was reported

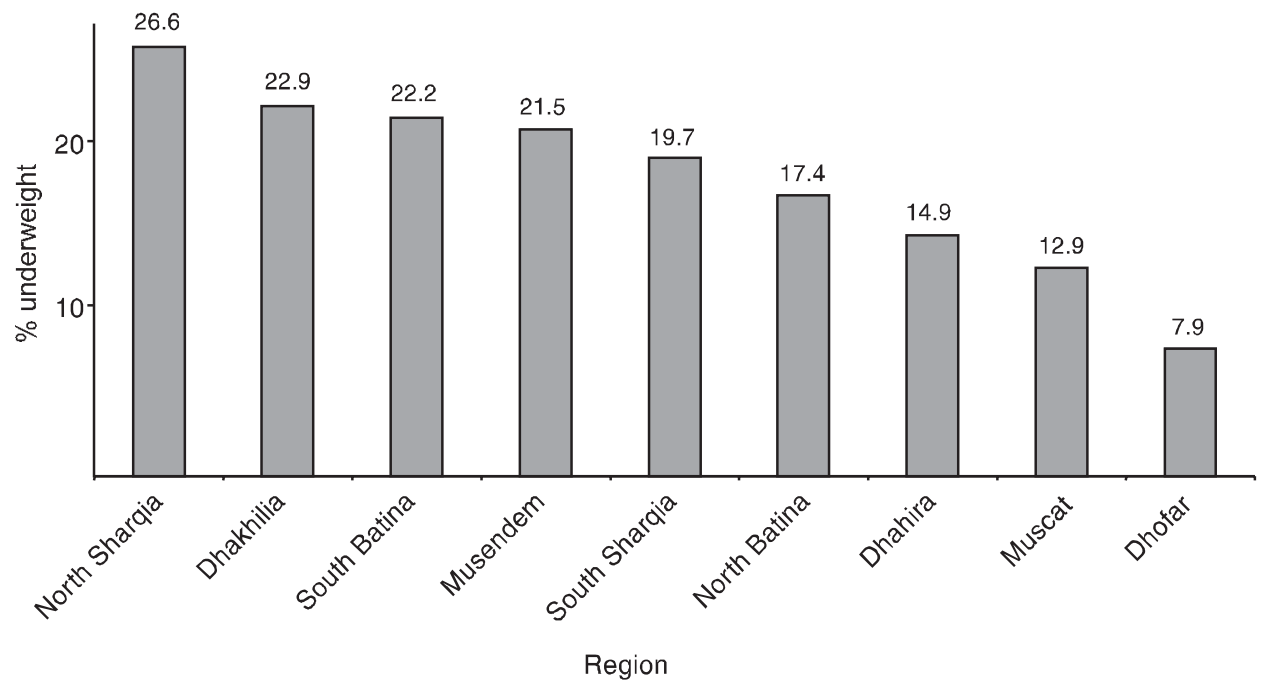

Figure 1 Regional distribution and classification of underweight in various regions of Oman, 1999 


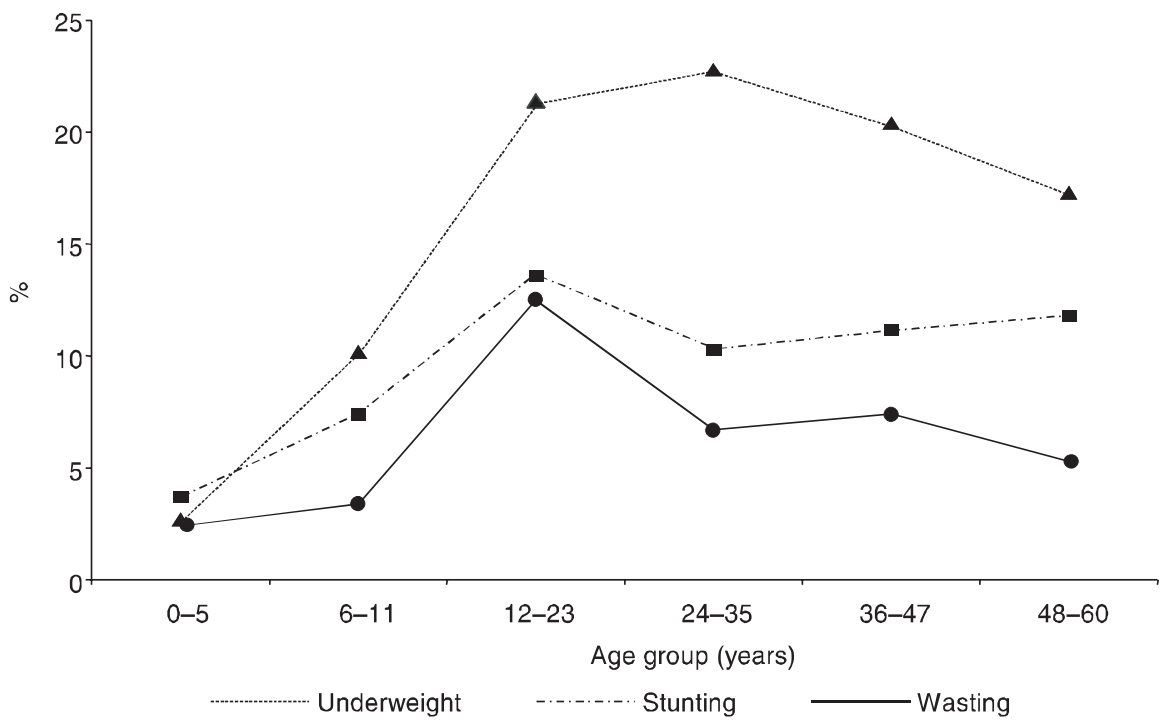

Figure 2 Age pattern of protein-energy malnutrition indicators among Omani infants and young children age $0-5$ years

to be $20.7 \%$ and it declined to $15.7 \%$ in 1995 and we found it to be $10.7 \%$.

The prevalence of child malnutrition in the Middle East has been reported to be $19 \%$; the countries with the lowest rates being the United Arab Emirates (8\%) and Morocco (6\%) [3]. Those countries are considered to have comparable economic and social conditions to Oman; however they appear to have a much better child nutritional status. Malnutrition not only compromises the health status of children and has an impact on child mortality but it can also impair the physical and mental capacity of the individual, which in turn could have a considerable economic impact on society and nations [12].
PEM is a result of a spectrum of social and economic factors. The Ministry of Health in Oman is taking active steps towards establishing public health interventions that take both clinical and social factors into consideration. Breastfeeding and complementary feeding support, early screening and management of PEM cases as well as social marketing to advocate and create awareness about the problem and its prevention are part of these efforts. In order to achieve the objectives of the Millennium Development Goals these efforts should continue at the same level of commitment and drive, in addition, support and collaboration from all sectors of the community is essential.

\section{References}

1. World Health Organization. Nutrition website (http://www.who.int/nutrition/en, accessed 15 April 2007).
2. De Onis et al M. The worldwide magnitude of protein energy malnutrition: an overview from the WHO Global Database on 
Child Growth. Bulletin of the World Health Organization, 1993, 71(6):703-12.

3. Galal O. Nutrition related health patterns in the Middle East. Asia Pacific journal of clinical nutrition, 2003, 12(3):337-43.

4. Amine $\mathrm{E}$ et al. Nutrition status survey in Oman and Bahrain. Report of the United Nations Children's Fund. Muscat, Oman, United Nations Children's Fund, 1980.

5. Mussaigher AO. Study of health and nutritional status of Omani families. Report of the United Nations Children's Fund. Muscat, Oman, United Nations Children's Fund, 1992.

6. Suleiman AJM, Al-Riyami A, Farid SM. Oman family health survey 1995: Principal report. Muscat, Ministry of Health, 2000.

7. De Onis $\mathrm{M}$ et al. for the WHO Multicenter Growth Reference Study Group. Measurement and standardization protocols for anthropometry used in the construction of a new international growth reference. Food and nutrition bulletin, 2004, 25(suppl. 1):S27-36.
8. United Nations Millennium Declaration (A/RES/55/2). Resolution adopted by the United Nations General Assembly, Fiftyfifth session, Agenda item 60(b), September 2000.

9. Measuring change in nutritional status. Geneva, World Health Organization, 1983.

10. Physical status: the use of and interpretation of anthropometry; report of a WHO expert committee. Geneva, World Health Organization, 1995 (Technical Report Series, No. 854).

11. De Onis M, Frongillo EA, Blössner M. Is malnutrition declining? An analysis of changes in levels of child malnutrition since 1980. Bulletin of the World Health Organization, 2000, 78(10):1222-33.

12. Pelletier DL et al. The effects of malnutrition on child mortality in developing countries Bulletin of the World Health Organization, 1995, 73(4):443-8. 